\title{
Experimental and Numerical Study of Strength Prediction of Cold Forged Parts Based on the Chaboche Combined Hardening Model
}

\author{
Yasuharu Shinkai*, Osamu Kada*, Ryuichi Nishimura ${ }^{\dagger}$, \\ Hiroki Narumiya* and Nobuo Yoshikawa* \\ * Steel Research Laboratories, R\&D Laboratories, Nippon Steel Corporation \\ 20-1 Shintomi, Futtsu, Chiba 293-8511, Japan \\ E-mail: shinkai.45k.yasuharu@jp.nipponsteel.com \\ Web page: https://www.nipponsteel.com/en/ \\ $\dagger$ Steel Research Laboratories, R\&D Laboratories, Nippon Steel Corporation \\ 1-8 Fuso-cho, Amagasaki, Hyogo 660-0891, Japan \\ * Kyushu R\&D Lab., R\&D Laboratories, Nippon Steel Corporation \\ 1-1 Tobihata-cho, Tobata-ku, Kitakyushu, Fukuoka 804-8501, Japan
}

\begin{abstract}
The high manufacturing costs of heat-treated cold forged parts has necessitated the possible elimination of the heat treatment process for improving their mechanical properties. In such a scenario, the strength of the parts can be determined by the degree of work hardening during cold forging; moreover, optimizing the shapes of cold forged parts based on strength prediction via finite element analysis (FEA) can assist in realizing the weight reduction of these parts as well as the cost reduction. However, when the parts are subjected to tensile loads during operation in the opposite direction of compressive loads imposed during cold forging (the Bauschinger effect), predicting the strength of these parts using an isotropic hardening model is inappropriate because it overestimates their strength. Only a few studies have reported on FEA models that consider the influence of the Bauschinger effect in the field of bulk forming [1].

In this study, a strength prediction method using a Chaboche combined hardening model [2] was investigated for predicting the strength of cold forged parts that are not subjected to heat treatment after cold forging. Simple shear tests [3-5] were performed to obtain stress-strain curves with reversed loading over a wide range of strains. The simple shear tests facilitated the accurate prediction of the strength of the cold forged parts.
\end{abstract}

\section{REFERENCES}

[1] S. Narita, K. Hayakawa, Y. Kubota, T. Harada, T. Uemori, "Effect of Hardening Rule for Spring Back Behavior of Forging", Procedia Eng. (ICTP 2017), 207(2017), 167-172.

[2] J.L. Chaboche, G. Rousselier, "On the plastic and viscoplastic constitutive equations - Part I: rules developed with internal variable concept", J. Pressure Vessel Technol., 105(1983), 153-158.

[3] N. Suzuki, S. Hiwatashi, A. Uenishi, T. Kuwayama, Y. Kuriyama, X. Lemoine, C. Teodosiu, J. Jpn. Soc. Technol. Plast. SOSEI-TO-KAKO, 46(2005), 636-640.

[4] N. Yoshikawa, K. Tamura, O. Kada and T. Yoshida, Proc. 68th JSTP Autumn Conference, (2017), 149-150.

[5] S. Shirakami, Y. Tsunemi, T. Yoshida and T. Kuwabara, "Work-hardening behaviour of sheet steels in large strain regions and its simple approximation", J. Phys. Conf. Ser. (NUMISHEET 2018), 1063(2018), 012107. 